\title{
Project Management Life Cycle Models to Improve Management in High-rise Construction
}

\author{
Andrey Burmistrov ${ }^{1 *}$, Maria Siniavina ${ }^{1}$ and Oksana Iliashenko $^{1}$ \\ ${ }^{1}$ Peter the Great St.Petersburg Polytechnic University, Polytechnicheskaya, 29, \\ St. Petersburg, 195251, Russia
}

\begin{abstract}
The paper describes a possibility to improve project management in high-rise buildings construction through the use of various Project Management Life Cycle Models (PMLC models) based on traditional and agile project management approaches. Moreover, the paper describes, how the split the whole large-scale project to the "project chain" will create the factor for better manageability of the large-scale buildings project and increase the efficiency of the activities of all participants in such projects.
\end{abstract}

\section{Introduction}

In the paper are presented some factors affecting the management of high-rise building projects and other projects, unique features of managing a complex project in terms of uncertainty at different stages of its life cycle, proposals that improve the quality of project management.

The objective of the current study was to demonstrate a possibility to improve project management in construction high-rise buildings through the use of various Project Management Life Cycle Models (PMLC models) based on traditional and agile project management approaches.

\subsection{Importance}

Currently, urbanization is global trend and in Russia as well - for example, federal government is planning some "organizational, regulatory and institutional measures are required to streamline and accelerate the development of agglomerations as a basic condition for the development of the postindustrial economy in Russia in the medium term (for 6 years)" [1], in particular, it is considered that priority will be focused not only on Moscow and St. Petersburg, but also on 36 Russian agglomerations with a population more than 500 thousand people. [2] Because of constantly increasing of the cost of land in large cities and growing of population, it is obvious that the construction of high-rise buildings will also increase. (At the same time, we do not consider the construction of skyscrapers, which for the purposes of our paper can also be attributed to high-rise buildings). Consequently, the

*Corresponding author: olgakalinina@bk.ru 
relevance of the project management of exactly high-rise buildings construction will increase for construction companies.

\subsection{Specificity of high-rise buildings as an element of large cities}

At present, not only in Russia there are no single criteria for concepts, but also in the world: "multi-storey building", "high-rise building" and others. According to Emporis Standards, "A high-rise building is a structure whose architectural height is between 35 and 100 meters. A structure is automatically listed as a high-rise when it has a minimum of 12 floors, whether or not the height is known. If it has fewer than 40 floors and the height is unknown, it is also classified automatically as a high-rise. A multi-story structure between 35-100 meters tall, or a building of unknown height from 12-39 floors. Example buildings: The Lloyd's Building (London, United Kingdom), Lever House (New York City, U.S.A.), Hansa-Hochhaus (Cologne, Germany)" [3]. In Russia, various definitions of the term "high-rise building" are used, for example, experts indicate that high-rise building is a building with hight more than $75 \mathrm{~m}$ (more than 25 floors) [4], according to [5] tall buildings are considered to be more than 75 meters high and up to 400 meters, and according to [6] high-rise residential and public buildings up to 150 meters high are considered residential buildings with a height of more than $75 \mathrm{~m}$, public buildings - more than $50 \mathrm{~m}$ ). Different definitions of high-rise buildings in the Russian Federation, see in [7].

In comparison with buildings of lower number of floors, high-rise buildings have the following features: as part of the system of the "city" system, they also touch issues of aesthetics, traffic management and in a broader sense sustainable urban development. From the point of view of the internal arrangement, higher demands are placed on high-rise buildings in terms of reliability, resistance to wind loads, and so on. The processes of creation and operation of high-rise buildings are also subject to higher requirements: engineering surveys, design, construction, etc.

In general, it can be certified that a high-rise building as a unique engineering and organizational system has a much higher complexity than low-rise buildings, this complexity is characteristic both for the system itself (the high-rise building) and for all the processes associated with the creation of this systems, including those with higher responsibilities, risks, investments, etc.

Due to this technology, the management of high-rise building projects requires the use of methods and tools that are designed to overcome the ever-increasing uncertainty and complexity of the life cycle processes of high-rise buildings.

\section{Methods}

In this paper, the data obtained from the scientific and periodicals, which indicate the quality status of project management in Russia and in the world, and some methods that are available to improve project management are being considered.

According to Lean Construction Institute (LCI), $70 \%$ of all construction projects are over budget $\&$ delivered late. Construction labor efficiency and productivity has decreased, while all other non-farming labor efficiency has doubled or more since the $1960 \mathrm{~s}$. Currently, $70 \%$ of projects are over budget and delivered late. [8]

According to PMI research, organizations lose \$ 109 million for every \$ 1 billion which was invested in projects and programs [9]. The KPMG study provides data that only $31 \%$ of all respondents' projects came within $10 \%$ of budget in the past 3 years, and just $25 \%$ of projects came within $10 \%$ of their original deadlines in the past 3 years. [10]

The reasons for the lack of success of projects are actively studied all over the world, and tools for improving project management are also offered. In particular, the implementation 
of BIM is proposed; Lean Construction [11]; Project Definition Rating Index (PDRI) for Building Projects [12], [13], "project implementation process based on the passage of strictly defined stages and milestones" (Stage-Gate Process,), "complex project monitoring system" (Control Tower ) [14] and many other tools.

\section{Results}

Practitioners and researchers estimate the lack of elaboration elaboration of project requirements at the initial stages is the main factor of the project's failure. As indicated in [13], industry practitioners are perceiving that early planning efforts in the project life cycle have a greater impact on the success of planning delivery. [15] McKinsey experts also consider that it is necessary to implement a system of a phased project management system that provides the suspension and completion of inefficient projects in the early stages. [14]

The research [16] indicates that the top five causes of troubled projects were:

1. Requirements: Unclear, lack of agreement, lack of priority, contradictory, ambiguous, imprecise.

2. Resources: Lack of resources, resource conflicts, turnover of key resources, poor planning.

3. Schedules: Too tight, unrealistic, overly optimistic.

4. Planning: Based on insufficient data, missing items, insufficient details, poor estimates.

5. Risks: Unidentified or assumed, not managed.

Similar views are expressed by Russian practitioners: "the main factors of project's failure:

1. Mistaken or incorrect definition of the main parameters at the start of the project (cost, timing).

2. Abnormality of the technology of project management, design and construction.

3. Formation of false goals ("technological death").

The cause of theseis defects in the project management system. "[17]

Besides the tools for the improvement described above, the experience of the industry which learns new methods and models of project management - IT industry faster that others can be used to improve the system of construction project management (including construction of high-rise buildings). The answer to the growing uncertainty and complexity of software development was the development of Agile based technologies.

However, in construction as opposed to IT industry, as a rule, project management models historically based on the PMI model are applied. This is a linear ("waterfall") model, which is the most efficient, but less flexible (is non-tolerant to changes). [18,19] This is understandable and appropriate, since buildings can not be reconstructed by "sprints", as in Scrum. Therefore, it seems that Flexible Project Lifecycle Management Models (models of project life cycle management) have no place in construction projects. However, it just seems. Firstly, stages of construction projects are heterogeneous (shown in the Table 1 below), and, secondly, there are several flexible (agile) project management models.

\subsection{Heterogeneity of stages of construction projects}

Let us consider the Influence and Expenditure Curve for the Project Life Cycle model (see Figure 1), which identifies the conceptual relationship between influence and expenditure in a project life cycle. 


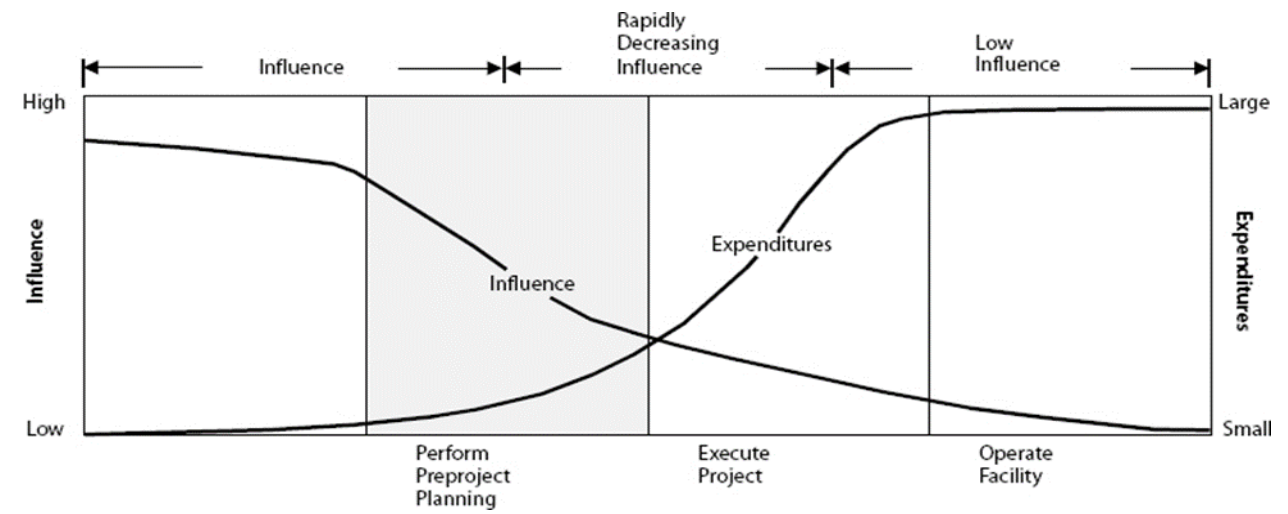

Fig. 1. Influence and Expenditure Curve for the Project Life Cycle

The curve labeled "influence" in Figure 1 reflects a company's ability to affect the outcome of a project during various stages of a project. The diagram illustrates that it is much easier to influence a project's outcome during the project planning stage when expenditures are relatively minimal than it is to affect the outcome during project execution or operation of the facility when expenditures are more significant. [20]

As we see that the key characteristics that affect project management (costs and possibility of influencing the project) vary with stage of the life cycle in opposite directions, which drastically changes the requirements for methods and models of project management.

\subsection{Project Management Life Cycle Models (PMLC models)}

Robert K. Wysocki highlights following PMLC models (see Figures 2 and 3):

Linear model

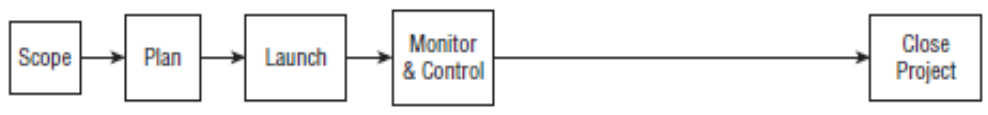

Incremental model

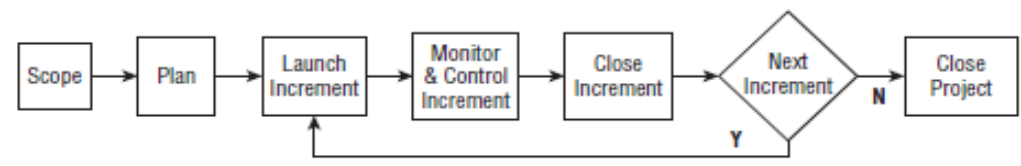

Fig. 2. Two models based on Traditional Project Management Approaches

Iterative model

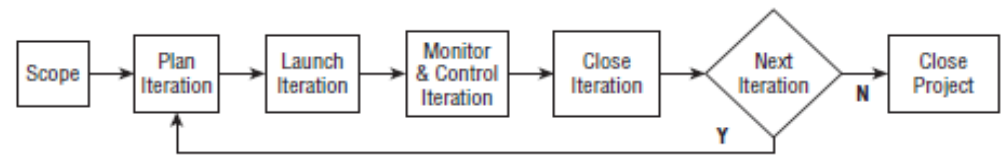

Adaptive model

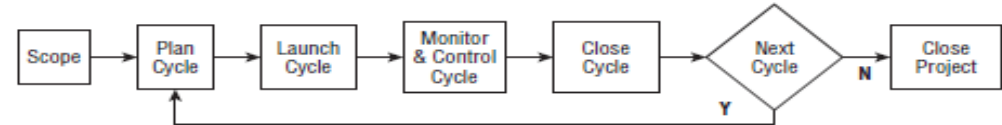

Extreme model

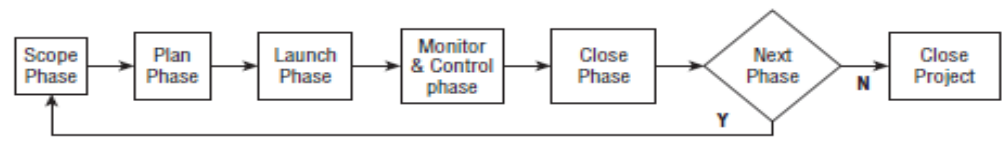

Fig. 3. Three models based on Agile Project Management Approaches, Source: [21]. In Russian, see the review of these models in [22]. 


\subsection{High-rise construction project can be viewed a sort of project chain}

High-rise construction project can be viewed a sort of project chain, at least, on starting position. Separate links are separate stages of the overall project. This follows from the fact that, in the case of increased attention to the early stages, the identified unpromising projects can be terminated at the Concept or Design stage (in order to avoid higher costs in the future). In addition, from Table 1 you can clearly see that the different Lifecycle Stage for a complex project is very different. Thus, we can consider the Concept and Design stages as separate projects (entering the chain) and use for them different models of project lifecycle management.

Table 1. Characteristics of different Stage of Project Lifecycle in Development (e.g. for high-rise buildings)

\begin{tabular}{|l|l|l|l|l|l|}
\hline $\begin{array}{c}\text { Project } \\
\text { Lifecycle Stage }\end{array}$ & $\begin{array}{c}\text { Work } \\
\text { volume and } \\
\text { costs }\end{array}$ & $\begin{array}{c}\text { Possibility to } \\
\text { influence the } \\
\text { project }\end{array}$ & $\begin{array}{c}\text { Cost of making } \\
\text { changes }\end{array}$ & $\begin{array}{c}\text { Goals, } \\
\text { Requirements, } \\
\text { Solution }\end{array}$ & $\begin{array}{c}\text { Management } \\
\text { Life Cycle } \\
\text { Model }\end{array}$ \\
\hline Concept & Low & Very High & Low (x 1)** & Unclear & $\begin{array}{c}\text { Extreme or } \\
\text { Adaptive model }\end{array}$ \\
\hline $\begin{array}{l}\text { Design \& } \\
\text { Planning }\end{array}$ & Medium & High & Medium (x 5) & Partially Clear & Iterative model \\
\hline $\begin{array}{l}\text { Procurement } \\
\text { and } \\
\text { Construction }\end{array}$ & High & Medium & High (x 12) & Clear & $\begin{array}{l}\text { Incremental or } \\
\text { Linear model }\end{array}$ \\
\hline Start up & Medium & Low & $\begin{array}{l}\text { Very High (x } \\
40)\end{array}$ & Very Clear & Linear model \\
\hline
\end{tabular}

Note:

*- We might notice that on this stage BIM is used quite similar to software or production prototype.

**- Quantitative estimates from INCOSE (The International Council on Systems Engineering (INCOSE) is a not-for-profit membership organization founded to develop and disseminate the interdisciplinary principles and practices that enable the realization of successful systems. http://www.incose.org/about) data for all kinds of complex projects. Here is given as a possible assessment for construction projects.

General approaches to the selection of the Management Life Cycle Model, which is recommended in [21] is shown in Figure 4.

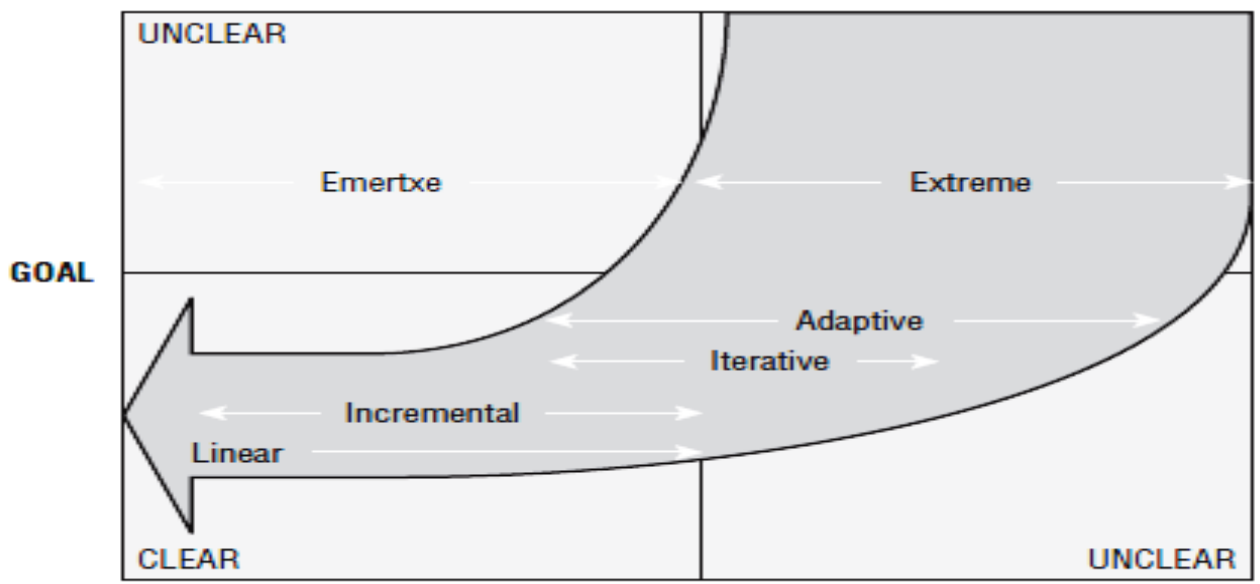

REQUIREMENTS \& SOLUTION

Fig. 4. PMLC approaches

As is shown above, these approaches can be used to manage complex construction projects. 


\section{Discussion}

The paper shows that an important improvement in the management of complex construction projects, including for high-rise buildings, is the increased attention to the initial stages of the life cycle of such projects. The characteristics of different stages of projects are considered, and a complex project of high-rise buildings with a high degree of uncertainty is proposed, not as a single project, but as a chain of projects.

The main link of such a chain should be a relatively independent project corresponding to the "Concept" stage, which is managed by the Extreme or Adaptive Management Life Cycle Model. These models have the greatest flexibility and the ability to change all the important elements of the "main" project at the very beginning. In this case, the participants in this project have more opportunities for an objective review of the project and, if it is found inexpedient or unprofitable - for rejection. As shown in paper [14], the more inefficient projects are rejected at an early stage, the more successful the remaining projects are.

If the construction is deemed expedient, the next project "Design \& Planning" is started, which is managed on the basis of the Iterative Management Life Cycle Model, which allows gradually getting more and more complete "prototypes" of the building under construction. The criteria for the success of the completion of this project should be the recognition by all participants of the fact that all important circumstances have been taken into account and that the uncertainty has been reduced to the level at which the next project - "Procurement and Construction", with the largest volumes of work and cost, can be managed by the least adapted to the changes, but the most economical model is the Incremental or Linear Management Life Cycle Model. If, in the course of the project "Design \& Planning", circumstances are revealed that it is inexpedient or unprofitable to continue the project, the "Design \& Planning" project also ceases, which also saves resources for all participants.

Also very important issues are ways to harmonize the interests of different stakeholders in the course of the "Concept" and "Design \& Planning" projects. These topics include, in particular, such components as the formation of a «common language», comprehension and formulation of shared values and on their basis shared goals by all participants, and implementing of systems engineering methods. These issues are critically important, but they are beyond the scope of this paper. They were considered by us, in particular, in [23] (on an example of projects on creation of transport systems in agglomerations).

\section{Conclusions}

In order to respond more flexibly to the increasing uncertainty and complexity of the buildings project, it is useful to decompose the whole large scale project and to split it into the "project chain". In this chain, the former stages of "Concept", and "Design \& Planning" become separate projects, executed sequentially. Then, for managing these projects, which are very different in their characteristics (and where the uncertainty is much higher than for the subsequent project "Procurement and Construction"), it will be possible to apply special Management Life Cycle Models based on Agile Project Management Approaches that are specifically designed for these conditions. In case of revealing inexpediency or ineffectiveness of the continuation of the work, it is easier to stop the "small" projects than the large-scale project. At the same time, for the project "Procurement and Construction", when the goals, requirements and solutions are already defined, it is advisable to use the traditional Incremental or Linear Model Management Life Cycle Model.

In summary, the split the whole large-scale project to the "project chain" will create the factor for better manageability of the large-scale buildings project and increase the efficiency of the activities of all participants in such projects. 


\section{References}

1. The plan of measures ("road map") "Development of agglomerations in the Russian Federation: The Economic Development Ministry of the Russian Federation. 19.11.2015.

2. Priority project passport "Safe and quality roads" (approved by the Presidium of the presidential Council of the Russian Federation for strategic development and priority projects (Protocol of 21 November 2016. № 10.

3. URL: https://www.emporis.com/building/standard/3/high-rise-building

4. Yu. Granik. Energy saving, 2, 92 (2004)

5. URL: http://docs.cntd.ru/document/1200042296

6. Russian State Standard TSN 31-332-2006

7. Standards of urban design, Moscow region (app. the resolution of the Government of Moscow region from August 17, 2015 N 713/30).

8. URL: http://blog.trestlescs.com/an-overview-of-lean-construction

9. Project Management Institute: Pulse of the Profession 2014 - The High Cost of Low Performance/

10. URL: https://assets.kpmg.com/content/dam/kpmg/pdf/2015/04/Global-ConstructionSurvey.pdf

11. URL: http://blog.trestlescs.com/an-overview-of-lean-construction

12. The Construction Industry Institute. (1999). Project Definition Rating Index (PDRI) Building Projects. Implementation Resource 155-2, Austin, TX.

13. Wang, Y.-R. \& Gibson, G. E. (2002). Using PDRI for project risk management: an empirical study of current practices. Paper presented at PMI ${ }^{\circledR}$ Research Conference 2002: Frontiers of Project Management Research and Applications, Seattle, Washington. Newtown Square, PA: Project Management Institute.

14. URL: http://vestnikmckinsey.ru/transport-infrastructure-and-logistics/krupnyheproektyh-klyuchevyhe-faktoryh-uspekha

15. I. Ilin., Kalinina O.V., Levina A.I., Iliashenko O.Yu. MATEC Web of Conferences, 83, 2016. Article number 05028.

16. URL:

http://www.pmsolutions.com/audio/Strategies_for_Project_Recovery_Research_Repo rt.pdf

17. URL: http://proestate.pro/images/proestate/2017/prezentacii/are1/GennadijKirkin_Irbis.pdf

18. V. Glukhov et al Lecture Notes in Computer Science. 2014. 8638 LNCS. Pp. 509-518.

19. I. Ilin, Anisiforov A.B. WSEAS Transactions on Business and Economics. 2014. 11. Pp. 757-764.

20. The Construction Industry Institute. (1995). Pre-Project Planning Handbook. Special Publication 39-2, Austin, TX.

21. R. Wysocki. Effective Project Management: Traditional, Agile, Extreme. Seventh Edition. (John Wiley \& Sons, Inc., 2014)

22. D. Butin, A. Burmistrov. The life cycle model of the project: comparative analysis / Collection: Week of science SPbSPU materials of scientific conference with international participation. Polytechnic University of Peter the Great, 2016. P.310-312. 
23. V. Schwetsov, A. Burmistrov, V. Morozov. Stages of Modernization an Effective Transport Management System in Russian Agglomerations: Invitation to Discussion, Collection: Transport planning and modelling: II International scientific-practical conference; SPbGASU. - SPb2017. - 341 p. P.298-307 